\title{
A Decade of Modest Convergence in Geographic Variation in Per Capita Medicare Fee-for-Service Expenditures: Taxation Without Representation Is Not Sustainable; Is It Time for Taxpayer and Consumer Engagement?
}

\author{
William B. Weeks, MD, PhD, MBA ${ }^{\top}$ (1), Grace H. Huynh, MD, $P h D^{\top}$, and \\ James $N$. Weinstein, DO, MS \\ 'Microsoft Research, Microsoft Corporation, Redmond, WA, USA; ${ }^{2}$ The Dartmouth Institute, Lebanon, NH, USA; ${ }^{3}$ Kellogg Business School, Evanston, \\ IL, USA; ${ }^{4}$ Tuck Business School, Hanover, NH, USA.
}

J Gen Intern Med 35(12):3736-9

DOI: $10.1007 / \mathrm{s} 11606-020-05702-8$

(c) Society of General Internal Medicine 2020

$\mathrm{W}$ asteful healthcare spending persists ${ }^{1}$ but is concentrated and amenable to change: Hospital Referral Regions (HRRs) with higher per capita expenditures provide more low-value care, ${ }^{2}$ and more wasteful Accountable Care Organizations reduce low-value care use after entering value-based payment plans. ${ }^{3}$ We hypothesized that increasing adoption of value-based payment models - introduced by the Centers for Medicare and Medicaid Services (CMS) in 2010 and designed to reduce waste - might reduce geographic variation in per capita healthcare spending and slow per capita expenditure growth in higher spending areas. To explore this hypothesis, we examined recent CMS data.

\section{METHODS}

From CMS, for 2007-2017, at the HRR level, we obtained fee-for-service beneficiaries' Part A and B standardized per capita expenditures (eliminating expenditures for graduate medical education and disproportionate share, locality pay, and alternative payment model differentials) disaggregated into 16 service categories listed in the Table 1 (data obtained at http://www.cms.gov/research-statistics-data-and-systems/ statistics-trends-and-reports/medicare-geographic-variation/ gv_puf.html).

This work used publicly available data and was determined to be "Not Human Subjects Research" by Dartmouth College's Committee for the Protection of Human Subjects (CPHSOOO28121).

Received November 13, 2019

Revised January 3, 2020

Accepted February 3, 2020

Published online February 19, 2020
We grouped per capita service-specific expenditures into "episodic" (like inpatient and home health care) and "service" (like procedures and evaluation and management (E\&M) visits) care categories; "total" per capita expenditures are their sum. To determine whether geographic variation in per capita total, episodic, and service care expenditures converged between 2007 and 2017, we calculated 3 commonly used measures of geographic variation, ${ }^{4}$ described in the Figure 1 legend.

We categorized HRRs into quintiles of total per capita expenditures in 2007 and calculated service-specific compound annual inflation rates (CAIRs) in the periods 2007-2010 (before value-based payment plans), 2010 2014 (early implementation), and 2014-2017 (late implementation).

\section{RESULTS}

Between 2007 and 2017, while all 3 measures of geographic variation in expenditures on episodic and service care fell slightly, only the extreme ratio for episodic care fell substantially (Fig. 1).

In 2007, per capita expenditures on every service category except outpatient hospital care increased when moving from lower to higher total spending quintiles (Table 1). Between 2007 and 2010, CAIRs did not exhibit any patterns across 2007-defined total spending quintiles, though CAIRs were generally high. Between 2010 and 2014, CAIRs were substantially lower (and negative) for many episodic care categories, procedures, testing, imaging, and durable medical equipment (DME). Between 2014 and 2017, growth accelerated in all categories save skilled nursing facilities, long-term care hospitals, E\&M, DME, and ambulance care; further, overall, episodic, and outpatient hospital care per capita growths were highest for 2007's lowest spending quintile and lowest for 2007's highest spending quintile. The lowest and highest 


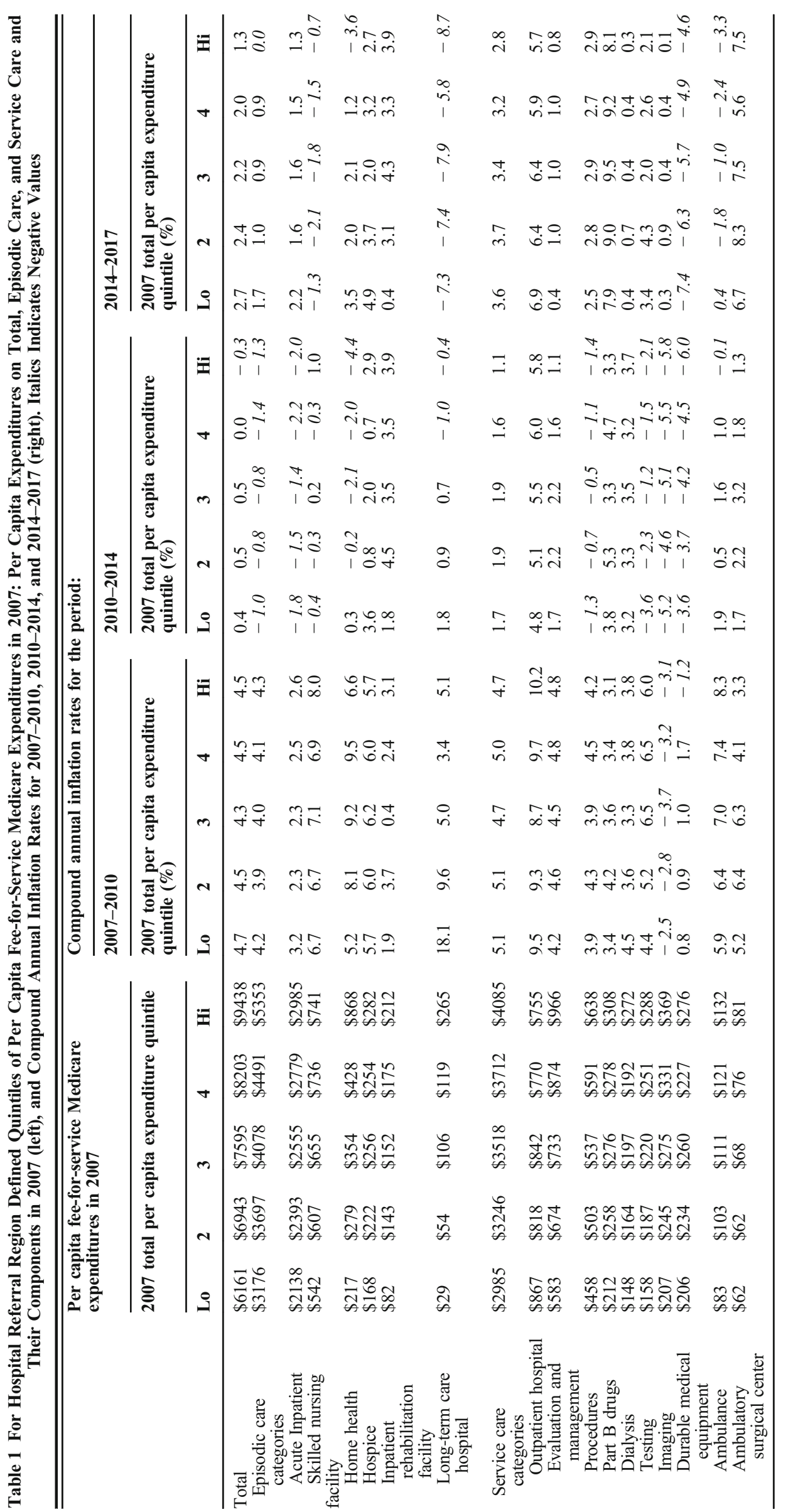




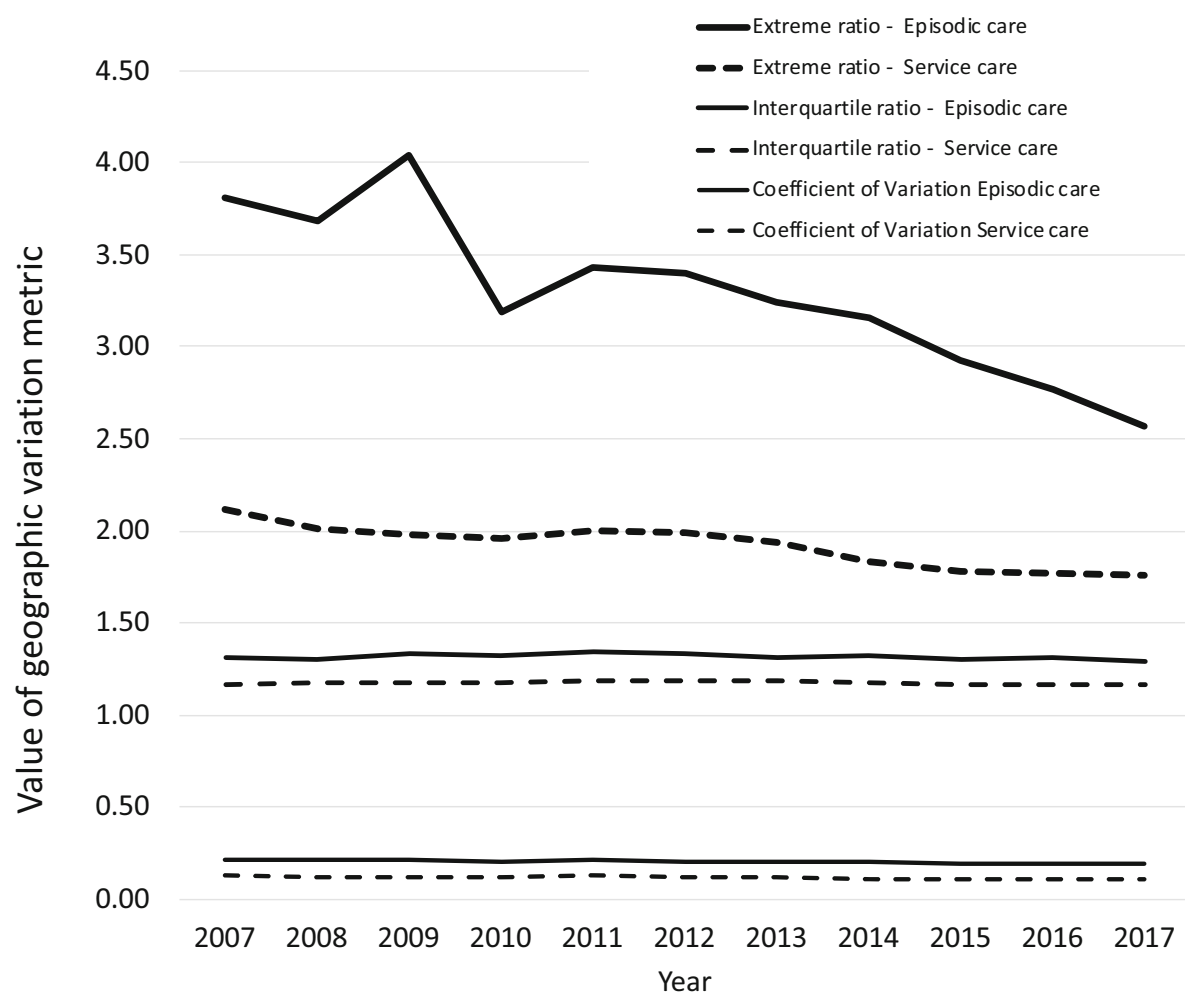

Figure 1 For 2007 to 2017, measures of geographic variation in per capita Medicare fee-for-service standardized expenditures on episodic (filled line) and service (dotted line) care. The measures are the extreme ratio (the highest divided by lowest value), the interquartile ratio (the 75 th percentile divided by the 25 th percentile value), and the coefficient of variation (the mean divided by the standard deviation).

spending quintiles in 2007 retained those designations in 2017 (data not shown).

\section{DISCUSSION}

Between 2007 and 2017, geographic variation in per capita fee-for-service Medicare expenditures modestly converged for episodic care facilitated by slightly higher episodic care CAIRs in low spending regions, particularly after 2014. For many care categories, cost growth dropped during early valuebased payment implementation, then increased. While testing, and imaging demonstrated low (or negative) growth rates - perhaps indicating some waste reduction-low absolute values of their per capita costs value limited their overall cost-growth impact.

While our analysis was observational, used standardized expenditure data that could not account for changes in demand or pricing, and could not specifically identify low-value service, it suggests that overall service consumption patterns have not dramatically changed. It is encouraging that extreme ratios for episodic care are falling; however, it is discouraging that growth reductions in 2010-2014 have not continued (though growth remains lower than before value-based payments were introduced).

Nonetheless, should the per capita expenditure CAIRs that we calculated persist, per capita spending in the highest and lowest spending quintiles will not equalize until 2075. The Medicare Trust Fund is anticipated to become depleted in 2026; after that, Medicare Trustees have proposed increasing the Medicare Tax to $3.81 \%$ or immediately reducing expenditures by $19 \% .^{5}$ Neither seems plausible, and the incremental spending changes that we found will not address the problem.

Heretofore, efforts to engage providers in reducing per capita expenditure growth have had little impact on reducing unnecessary services, like avoidable hospitalization. ${ }^{6}$ Perhaps engaging taxpayers and healthcare consumers would facilitate a more rapid waste reduction and expenditure convergence. Making transparent the persistent indirect taxation of those living in low-spending regions by those living in high-spending ones might be motivating to them: should new local tax receipts be required to fill gaps between a national per capita Medicare subsidy and local per capita Medicare spending, politicians and patients might align to reduce wasteful spending, converge spending across geographic settings, and lower Medicare per capita cost growth.

Corresponding Author: William B. Weeks, MD, PhD, MBA; Microsoft Research Microsoft Corporation, Redmond, WA, USA (e-mail: wiweeks@microsoft.com).

\section{Compliance with Ethical Standards:}

Conflict of Interest: The authors declare that they have no conflict of interest. 


\section{REFERENCES}

1. Shrank WH, Rogstad TL, Parekh N. Waste in the US Health Care System: Estimated Costs and Potential for Savings. JAMA 2019

2. Colla CH, Morden NE, Sequist TD, Schpero WL, Rosenthal MB. Choosing wisely: prevalence and correlates of low-value health care services in the United States. J Gen Intern Med 2015;30:221-8

3. Schwartz AL, Chernew ME, Landon BE, McWilliams JM. Changes in Low-Value Services in Year 1 of the Medicare Pioneer Accountable Care Organization Program. JAMA Intern Med 2015;175:1815-25.

4. Weeks WB. Geographic Variation in Medicare Expenditures, 2003-2012 JAMA Intern Med 2016;176:405-7.
5. Mnuchin S, Acosta R, Azar A, Berryhill N, Verma S. 2019 Annual Report of the Boards of Trustees of the Federal Hospital Insurance Trust Fund and the Federal Supplementary Medical Insurance Trust Fund. https://www. cms.gov/Research-Statistics-Data-and-Systems/Statistics-Trends-andReports/ReportsTrustFunds/Downloads/TR2019.pdf. Washington, DC: Boards of Trustees of the Federal Hospital Insurance Trust Fund and the Federal Supplementary Medical Insurance Trust Fund; 2019.

6. McWilliams JM, Chernew ME, Landon BE. Medicare ACO Program Savings Not Tied To Preventable Hospitalizations Or Concentrated Among High-Risk Patients. Health Affairs (Project Hope) 2017;36:2085-93.

Publisher's Note Springer Nature remains neutral with regard to jurisdictional claims in published maps and institutional affiliations. 